\title{
obituary
}

\section{Vincent du Vigneaud, 1901-1978}

Vincent DU Vigneaud, Professor Emeritus of Biochemistry at Cornell University Medical College in New York City and, since 1967, Professor of Chemistry at Cornell University in Ithaca, New York, died, after a long illness, on 11 December 1978, in White Plains, New York.

Professor du Vigneaud, born in Chicago in 1901, was of French ancestry, the son of Alfred and Mary Theresa du Vigneaud. In 1918, he entered the University of Illinois in Urbana. Here he developed a sincere dedication to chemistry under the influence of C. S. Marvel, who taught him organic chemistry, H. B. Lewis, who lectured on cystine and cysteine, and last, but not least, W. C. Rose, who, in 1923 , returning from a trip to Toronto, gave a talk on insulin. recently discovered there by Banting and Best. This lecture on the exciting new hormone made a lasting impression on the young student. In later years he liked to consider sulphur as the guiding principle of his research, leading him from insulin, through biotin and penicillin, to oxytocin and vasopressin ( $A$ Trail of Research by V. du Vigneaud, Cornell University Press, 1952). During the years in Urbana, he met Zella Zon Ford, an English major at the same University, his future wife and his constant source of encouragement until her death in 1977.

After graduation, he spent a short time in industry, in the laboratory of a hospital and taught chemistry in the School of Medicine at the University of Pennsylvania. Yet, the attraction of biochemistry was strong, and soon he joined Professor J. R. Murlin in the School of Medicine at the University of Rochester to work as a graduate student on the chemistry of insulin. This hormone was obtained in crystalline form by J. J. Abel, but the procedure was not readily reproducible and the young du Vigneaud demonstrated his exceptional experimental skills by preparing crystalline insulin in substantial quantity. Professor Murlin, himself a physiologist, gave him much freedom to pursue the origin of the alkali-labile sulphur in insulin, a study

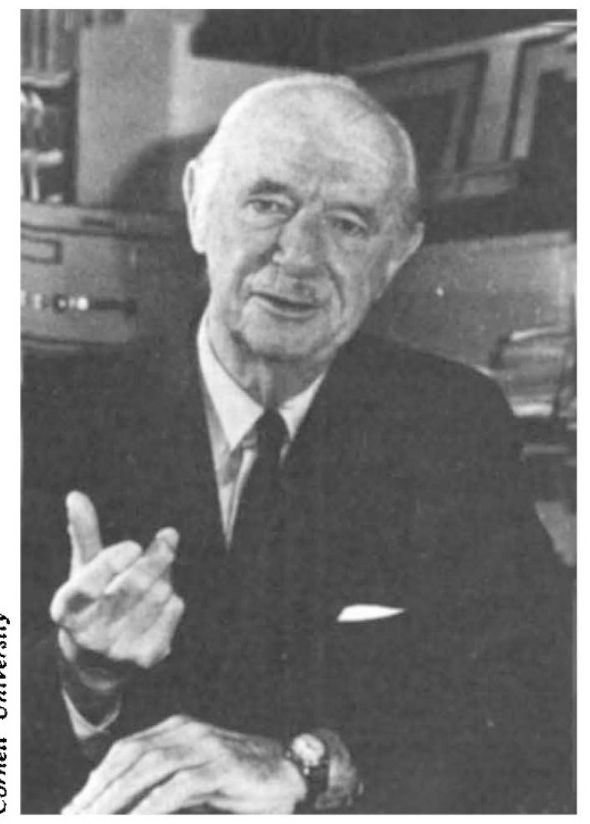

which became his dissertation, The Sulfur in Insulin.

With a fellowship from the National Research Council, he joined Professor John J. Abel at The Johns Hopkins University Medical School. Here his insulin work was continued, in collaboration with Oscar Wintersteiner and Hans Jensen. The Fellowship was extended for a second year, which he spent in Germany at the Kaiser Wilhelm Institute in Dresden, in Max Bergmann's laboratory, where, working with Leonidas Zervas, he became involved in peptide synthesis. The studies abroad were concluded with shorter stays with Professor George Barger at the University of Edinburgh and with Dr Charles Harrington (later Sir Charles) at the University College Hospital Medical School in London.

Dr du Vigneaud returned to the United States to join the faculty of the Department of Physiology, headed by W. C. Rose, of the University of Illinois in Urbana, his alma mater. The stimulating atmosphere there is best shown by mentioning some of his colleagues: C. S. Marvel, R. C. Fuson, R. L. Shriner and last, but not least,
Roger Adams. Still, he yielded to the temptation of more independence in research and in 1932, at the age of 31, accepted an invitation from the George Washington University School of Medicine to head their Department of Biochemistry. Other invitations followed and in 1938 he made the decisive move, to New York City, to become Professor of Biochemistry and Head of the Department of Biochemistry at Cornell University Medical College, the scene of his greatest achievements. There du Vigneaud remained until his formal retirement in 1967 when he joined the Chemistry Department of Cornell at Ithaca, New York, as Professor of Chemistry. He carried out an active research programme for seven more years, when his creative work was ended by sudden illness.

It might be impractical to try even to sketch here du Vigneaud's contributions to the chemistry of insulin, his work on homocysteine and transmethylation, or on biotin. Let us point only to the leitmotif in these studies: they all contain sulphur. The surprising solubility of insulin in liquid ammonia prompted the development of the reductive cleavage of benzyl and benzyloxycarbonyl groups with sodium in liquid ammonia, a method which later turned out to be crucial in his studies on penicillin and on oxytocin.

The penicillin experiments were carried out during the Second World War as part of a concerted effort between forty cooperating laboratories. The Cornell group, under du Vigneaud, first accomplished a synthesis of penicillamine. The synthesis of penicillin itself followed. The structure on which the synthesis was based, the thiazolidine-azlactone formula is now considered erroneous (although Sir Robert Robinson showed that it is a 'protomer' of the finally accepted thiazolidine- $\beta$ lactam structure). Accordingly, the du Vigneaud synthesis resulted in an inactive product, but this could be readily converted to a material with slight, but definite antibiotic activity. The active component was demonstrated to be penicillin, by the isotope 
dilution method and by its sensitivity to penicillinase.

At this point most researchers would have regarded the project as concluded. Not du Vigneaud. With his associates, he isolated penicillin $\mathrm{G}$ from the synthetic mixture through a series of purification steps, including the countercurrent distribution method developed about this time by Lyman C. Craig at the Rockefeller Institute, next door to Cornell. A crystalline salt of penicillin $G$ was obtained and shown to be identical with natural penicillin by an array of methods of physical chemistry, X-ray crystallography and biological activity. This unrelenting and uncompromising search for conclusive evidence was a characteristic feature of the research of du Vigneaud. The same standards were maintained when his interest turned to the peptide hormones, oxytocin and vasopressin.

The hormonal effects of extracts from the posterior lobe of the pituitary gland have been known since the turn of the century. In the late nineteentwenties, $O$. Kamm demonstrated the presence of two separate principles in the extracts, one oxytocic (quickening childbirth) and the other pressor and antidiuretic. A comment of Kamm on the relatively small molecular weight of the two hormonally active factors, oxytocin and vasopressin, sparked the interest of du Vigneaud. Although the penicillin studies interrupted his first attempts toward the isolation of the two peptide hormones $\mathrm{m}$ pure form, this effort was revived after the Second World War and led, in relatively short time, to the isolation of the pure peptides. Countercurrent distribution again played a major role in the success. Elucidation of the structures soon followed and in 1953 the endeavour was crowned by the synthesis of oxytocin, and later by the syntheses of lysine vasopressin and arginine vasopressin. These were epoch-making achievements. The 1955 Nobel Prize in Chemistry was awarded to Professor du Vigneaud "for his work on biochemically important sulphur-containing compounds, especially for the first synthesis of a polypeptide hormone.' Other awards, medals, honorary degrees received by him are too numerous to be mentioned here.

Many of us thought that having finished with oxytocin, Professor du Vigneaud would turn towards even more ambitious objectives, perhaps the synthesis of insulin. On such questions his answer was: 'Finished? We have just started.' And, indeed, the effort in the field of pituitary hormones was continued for almost twenty more years. Many of the results from his laboratory were trend-setting, such as a new synthesis of oxytocin by the stepwise strategy, an approach which was applied also to the synthesis of lysine vasopressin, and of numerous analogues of the two peptides. The availability of synthetic analogues permitted the exploration of the interaction between hormone and receptor. Functional groups were replaced by hydrogen, first the phenolic hydroxyl in oxytocin, then its single free amino group. Biologically active peptides were obtained. These studies gave new insight into hormonal activity and demonstrated the significance of architecture in peptides and proteins. In fact, Professor du Vigneaud liked to call oxytocin a "baby protein.' The body of information generated in this tireless effort is impressive: it appeared in about 200 publications, almost half of the total 'output' of du Vigneaud's published work.

The published reports, however, are certainly not the total of the du Vigneaud legacy. The daily contact with this exceptional man had a major influence on those of us who were fortunate enough to have spent some of our formative years in his laboratory. His account of declining a suggestion to accept responsibility for the synthesis of corticotropin, which at that time seemed to be more important than oxytocin, taught us to stick to commitments already made. By insisting on treating synthetic oxytocin with bromine-water to observe its cleavage into two fragments, as happens with natural oxytocin, he demonstrated the need for skepticism towards one's own results, at a time when nobody else had doubts about their correctness.

On his prompting, I had prepared a crystalline salt of synthetic oxytocin suitable for X-ray studies. A letter to Nature on the crystals was already typed when he came to my laboratory with a sample of natural oxytocin and requested that I repeat the crystallisation with natural oxytocin as well. Years after receiving the Nobel Prize, he still wanted to be sure that there was no difference between natural and synthetic preparations of the hormone. Scientific integrity was one of the lessons we could learn from him. Yet, his style, his flair for the important and his unshakeable optimism that the next major discovery is just around the corner were unique aspects of the man, which would be difficult to imitate.

Professor du Vigneaud is survived by his two children, Vincent du Vigneaud, Jr., an obstetrician and gynaecologist, and Marilyn Renee Brown, Assistant Professor of Pediatrics at the University of Rochester Medical Center. Those who were saddened by his departure also include his former associates, the 166 members of the 'V. du V. Club,' among them many distinguished scientists, including two Nobel laureates. Miklos Bodanszky

\section{Robert van den Bosch}

RoBert VAN DEN BosCh, Professor of Entomology and Chairman of the Division of Biological Control at the University of California, Berkeley, died while jogging on 19 November 1978. His death deprived the ranks of entomologists, ecologists, biological control specialists and environmentalists, world-wide, of an outstanding individual.

Van, as he was called by most who knew him, was born in Martinez, California on 31 March 1922. He received his BA in Physical Education from the University of California at Berkeley in 1943. From 1943 to 1946 he served as Deck Officer with the Amphibious Forces, US Naval Reserve, and saw heavy combat action in the Pacific. In 1947 he returned to the University of California, Berkeley as a student in entomology, receiving his $\mathrm{PhD}$ in that field in 1950.

In his professional career, besides being a researcher, a teacher, and an administrator in the Division of Biological Control and the Department of Entomological Sciences at the University of California, Berkeley, Van served as a member of the Board of Directors of the Rachel Carson Trust and a consultant to various national and international groups and institutions concerned with agricultural and environmental issues related to pest control. He was a fellow of the American Association for the Advancement of Sciences, and a Guggenheim Fellow.

The circuitous academic route followed by Professor van den Bosch was not as unusual as it might seem. In a communication written just before his death he clarified this by saying that bugs were his first love and that as a member of the Boy Scouts he was one of the rare ones who earned a merit badge in entomology. This was the major he chose when he came to the University of California as an undergraduate student in 1939. However, his interest and activities in athletics conflicted with the heavy laboratory schedule of an entomology major and so he shifted to the physical education major and there earned his AB degree. Following his service in World War II, however, he returned to his first and enduring loves: the University of California and Entomology. His keen intéllect, strong motivation and perseverance led Professors Ray F. Smith and E. Gorton Linsley to encourage him to work directly for his PhD, which he did under the direction of Professor Smith. As a fledgling PhD he became a member of the University of Hawaii faculty from 1949 to 1951 when he joined the University of California at 